\title{
Nações e estilos de economia política
}

\author{
JOÃO ANTONIO DE PAULA \\ HUGO E. A. DA GAMA CERQUEIRA \\ EDUARDO DA MOTTA E ALBUQUERQUE*
}

Nations and styles of political economy. This paper investigates the existence of national styles of political economy. The characteristics and determinants of the German, the Austrian, the French, and the English styles are suggested. Some methodological implications for the historical economic thought are outlined.

Key-words: national styles; political economy; economic discourse.

JEL Classification: B00; B40.

O texto a seguir inscreve-se no campo da história do pensamento econômico e sustenta que o seu desenvolvimento pressupõe entendê-lo como um capítulo de uma determinada sociedade nacional concreta. Isto é, que a economia política, em que pesem suas especificidades no referente a objetos-conceitos-métodos, é tributária da cultura, da fisionomia político-cultural de uma época e de uma região.

Neste texto assume-se que o pensamento econômico reflete, em algum sentido, o conjunto das circunstâncias histórico-culturais que o forjaram e que o viram nascer. Dizer isso - é importante frisar — não significa negar a existência de uma dimensão autônoma, interna, regida por leis e procedimentos analítico-científicos, determinante decisivo da constituição de todo campo específico de conhecimento. Significa, na verdade, interrogar a justeza da tese de Schumpeter sobre a existência de uma dimensão do pensamento econômico, a análise econômica, que seria imune a contaminações ideológico-políticas, eternamente voltada para um único objetivo - o desenvolvimento dos métodos de análise econômica no sentido de sua plena aproximação do prevalecente nas ciências exatas e naturais.

\footnotetext{
* Professores do Cedeplar - Universidade Federal de Minas Gerais. Rua Curitiba, 832, Belo Horizonte, MG. E-mails: jpaula@cedeplar.ufmg.br; hugo@cedeplar.ufmg.br; e albuquer@cedeplar.ufmg.br. A versão inicial deste artigo foi apresentada no XXIX Encontro Nacional de Economia. Os autores agradecem a Ramón Garcia Fernandez e Maria Cecília Boechat pelos comentários àquela versão, bem como aos pareceristas da REP por sua leitura atenta e pelas sugestões. Submetido: março 2004; aceito: maio 2006 .
} 
Assume-se aqui que o pensamento econômico, em que pese certa autonomia discursiva, certas exigências metodológico-conceituais, reflete o seu tempo e o seu lugar, expressa-se segundo estilos, metáforas, referências, interesses que transcendem o específico da análise econômica. Trata-se, assim, de entender o pensamento econômico, como, em alguma medida, refletindo o contexto nacional, as circunstâncias históricas que o ensejaram. De tal modo que é isto que explicaria a existência de estilos, de certos cacoetes definidores das diversas escolas nacionais de pensamento econômico, que dizem respeito tanto à forma quanto ao conteúdo de suas respectivas elaborações teóricas.

Registre-se, também, preliminarmente, que as relações entre o conhecimento e a sociedade que o geraram não são lineares, unívocas, imediatas ou transparentes; que este é um campo marcado pela ambigüidade, pela contradição, pela presença de resultados não esperados de certas ações. Trata-se, no essencial, de reconhecer e levar a sério a complexidade; de afastar, por inconsistência, os juízos simplificadores, que querem ver na realidade histórico-social o que ela não pode ser - a realização de uma racionalidade ilimitada, que se manifesta pela ascensão linear do erro ao acerto. Está implícito no que se vai defender aqui que as eventuais maiorias, que se formam em torno de certos paradigmas conceituais, não são nem a prova de sua efetiva universalidade, nem devem ser as senhas para a interdição do que foi considerado equívoco. Em sua guerrilha metodológica, Feyerabend mostrou, mais uma vez, que certos verdadeiros avanços do conhecimento só foram possíveis pela recuperação de idéias que tinham sido condenadas ao total esquecimento.

No essencial, vai se sustentar aqui que a pesquisa sobre a gênese e características dos "estilos nacionais de economia política" possibilita tanto compreender a especificidade da reflexão sobre economia, quanto vislumbrar a complexa trama de determinantes presentes na relação entre o conhecimento e a sociedade que o gera. ${ }^{1}$

Em uma conhecida passagem de Para a crítica da economia política, Marx esboça o central da história do pensamento econômico clássico, identificando tanto a sua temporalidade, quanto seus principais autores e obras quanto seu objeto unificador - a teoria do valor. O programa estabelecido por Marx (1974: 160 ss.) e enfrentado, em parte, nesta passagem, tem como essencial entender as razões profundas das diferenças entre França e Inglaterra no referente à economia política clássica, que elas criaram simultânea, convergente e diferentemente.

Ao lado dessa questão, um outro tema será considerado aqui para ajudar a compreender as relações entre sociedade e conhecimento. Trata-se do referente à revolução marginalista, ocorrida entre 1871-1874, e a sua posterior consolidação como ortodoxia, nos anos 1880-1890, como criação simultânea de Inglater-

\footnotetext{
${ }^{1}$ Naturalmente, ao tratar dos "estilos nacionais de economia política" não se está negando a existência de outros recortes igualmente relevantes para conformação das teorias econômicas, como aquele decorrente das perspectivas de classe, por exemplo.
} 
ra, Áustria e França, e as diferenças de estilo dessas versões da gênese do neoclassicismo. Como contraponto a esse conceito de afinidades, será discutido a trajetória singularíssima do pensamento econômico alemão em sua recusa aos paradigmas da economia política clássica e da ortodoxia neoclássica.

Inicie-se pela análise das diferenças entre França e Inglaterra no referente à economia política clássica.

No texto de Marx, Inglaterra e França aparecem, sobretudo, como realidades histórico-culturais. É por isso que ele pode agrupar entre os economistas ingleses Steuart e Adam Smith, que são escoceses, e, entre os economistas franceses, Sismondi, que é suíço. Significativa, nesse sentido, é a presença de economistas como John Law e Cantillon, escocês um, irlandês o outro, que, tendo realizado suas carreiras na França, são como que encarnações de uma complexa síntese de hibridismo desconcertante pelo que combinam das duas matrizes histórico-culturais.

Para Marx a economia política clássica teria nascido com as obras do inglês Petty e do francês Boisguillebert e teria sua conclusão-realização com as obras do inglês Ricardo e do "francês" Sismondi. Cento e cinqüenta anos de história — da consolidação da revolução burguesa na Inglaterra à Revolução Industrial, passando pela Revolução Francesa.

Se a economia política clássica nasce na Inglaterra e na França, ao final do século XVII e início do XVIII, tem-se em comum a afirmação da centralidade do valor trabalho, havendo diferença importante e cheia de conseqüências entre esses países, no referente aos desdobramentos da teoria do valor trabalho - diferença esta que é reveladora do essencial das trajetórias históricas dos dois países. Diz Marx:

"Um estudo comparativo sobre os trabalhos e o caráter de Petty e Boisguillebert, independentemente do que focalizaria a oposição real entre a Inglaterra e a França dos fins do século XVII e começos do século XVIII, conduziria à exposição da gênese do contraste nacional entre a economia política inglesa e a francesa. O mesmo contraste se repete no final com Ricardo e Sismondi.” (Marx, 1974: 160).

Onde o contraste, qual a razão da diferença, como ela se expressa? Marx não responde inteiramente a essas questões. Contudo, ele indicou o essencial do problema. Para ele tratava-se de entender por que na França foi tão difícil mantendo-se essa dificuldade ainda por muito tempo, de modo a incidir ainda hoje - assumir todas as conseqüências da vitória do modo de produção capitalista, vis-à-vis à ampla hegemonia política e cultural do individualismo e do liberalismo na Inglaterra.

Para Marx a grande diferença entre as concepções de economia política de franceses e ingleses pôs-se desde o início, com Boisguillebert, e permaneceu até a sua conclusão, com Sismondi. No centro dessa distinção está a denúncia que esses autores fizeram de aspectos centrais da dinâmica capitalista: o dinheiro e o grande capital industrial. Tanto Boisguillebert quanto Sismondi são capazes de 
entender a centralidade da teoria do valor trabalho como princípio unificador da economia política, mas ambos não são capazes de extrair todas as conseqüências da plena vigência das leis de valorização do capital: "Sismondi não está mais fechado na concepção de Boisguillebert de que o trabalho que põe valor de troca seja falsificado pelo dinheiro, mas assim como Boisguillebert denuncia o dinheiro, denuncia ele o grande capital industrial” (Marx, 1974: 167).

A questão então é entender como essa recusa do pensamento econômico francês em referendar algumas das implicações necessárias da lógica capitalista - o domínio do dinheiro e do grande capital - não o impediu de avançar na compreensão de aspectos centrais do funcionamento desse mesmo capitalismo. Mais que uma contradição, esse traço do pensamento econômico francês explicita o peso importante das determinações histórico-nacionais do conhecimento. É que, ao contrário da Inglaterra, a França sempre esteve no outro ponto extremo, no relativo ao absolutismo, às liberdades públicas e individuais. Se a França é, desde o início do século XVII, pelo menos, a exacerbação do poder absolutista, a Inglaterra vive, ainda mais precocemente, desde o início do século XIII, com a Carta Magna, a presença de limitações ao poder da monarquia, uma realidade que foi chamada de absolutismo mitigado. É essa tradição que marcará a trajetória político-institucional da Inglaterra até hoje - a longa experimentação de formas de garantia dos direitos individuais, uma permanente supremacia dos interesses dos homens de negócio sobre os privilégios aristocráticos. É essa a base tanto da mais arejada concepção de mercantilismo, que vai prevalecer na Inglaterra, quanto do enraizamento das prerrogativas da sociedade civil inglesa contra o discricionário do poder monárquico. Dessas tradições emergiram tanto o substrato das mentalidades, que possibilitaram o surgimento dessas criações intelectuais tipicamente inglesas - o empirismo, o liberalismo e o utilitarismo - , quanto a motivação política para as revoluções do século XVII, que consolidaram o poder burguês na Inglaterra. De tal modo que a economia política clássica é uma criação inglesa na mesma medida em que também é invenção inglesa uma certa concepção de mundo tomada como espaço da realização de interesses individuais, com base em escolhas hedonísticas e relações impessoais.

Muito outra é a ambiência histórica francesa. Lá prevaleceu, entre os séculos XVII e XIX, a mão pesada do estado absolutista em todo o seu poderio. Lá, ao contrário da afirmação dos interesses individuais, que é típica da realidade inglesa, prevalecerão a regulamentação e a interferência estatais, a concentração absoluta do poder monárquico, a ausência de instituições político-representativas capazes de vocalizar os interesses do "terceiro estado". É esse pano de fundo histórico que condicionará o pensamento econômico francês, que mesmo em seus momentos de maior adesão ao escrutínio do mercado como único regulador legítimo e racional da vida econômica — como em Walras — não poderá evitar de se ocupar da reforma social.

Trata-se, se for permitida certa leitura psicologizante, de ver o pensamento econômico francês como incapaz daquela ausência de culpa que permitiu aos ingleses levar a compreensão da economia ao seu mais alto grau, exatamente por- 
que disposto a explorar todas as suas conseqüências, até as mais eticamente problemáticas. É esse desassombro, essa disposição em ir até o fundo das implicações da lógica capitalista, que levou a que se dissesse ser a economia política uma ciência lúgubre, com algo de sinistro.

Aos franceses parece impossível ir tão longe, do que resultará uma estranha convergência, que unirá Boisguillebert, Proudhon e mesmo Walras. Diz Marx:

“[Boisguillebert] cada vez que se defronta com o caráter específico da riqueza burguesa, como no dinheiro, acredita na intromissão de elementos usurpadores estranhos irritando-se com o trabalho burguês sob uma das suas formas, ao passo que o glorifica sob outra forma (...) $\mathrm{O}$ socialismo francês na sua forma proudhoniana padece do mesmo mal nacional hereditário" (Marx, 1974: 162).

Compare-se, no mesmo sentido, as doutrinas econômicas de Adam Smith e Quesnay. Se ambas são tributárias do jusnaturalismo, a maneira como cada um desses autores encara a existência dos direitos naturais é bem diversa.

Para Quesnay, à semelhança das leis que regulam o movimento dos corpos celestes, existem leis naturais que regem a vida em sociedade. Quer se trate das leis naturais físicas ou morais, "tous les hommes et toutes les puissances humaines doivent être soumis à ces lois souveraines, instituées par l' Être Suprême; elles son immuables et irréfragables, et lesmeilleures lois possibles." (Quesnay, 1991a: 83). Entretanto, nada impede que a ordem social seja rompida pela adoção de leis positivas contrárias às leis naturais, o que explica a ênfase posta pelos fisiocratas na necessidade de instruir os homens nos princípios dessa ordem. Sem o conhecimento das leis naturais, "le gouvernments et la conduit des hommes ne peuvent être que ténèbres, égarements, confusion et désordres”. Note-se como, mesmo identificando a ordem natural com a liberdade de produzir e comerciar, Quesnay não hesita em condenar a divisão de poderes e afirmar o interesse geral contra os interesses particulares, pois a segurança e a prosperidade da nação passam a depender de uma autoridade soberana "superiéure à tous les individus de la societé et à toutes les entreprises injustes des intérests particuliers (...) [e que] toujours éclaire par l'évidence, institue les meilleures lois et les fasse observer exactement pour la sûreté de tous" (Quesnay, 1991b: 237-8).

Para Smith, ao contrário, a prosperidade econômica pode ser retardada, mas não detida, pela existência de leis positivas que violem a ordem natural. O progresso é assegurado pela existência de um princípio inscrito na natureza humana, do qual dependem tanto a opulência pública e nacional, como a privada. Trata-se "do esforço uniforme, constante e ininterrupto de todos os homens para melhorarem a sua situação (...) que é muitas vezes suficientemente poderoso para manter o progresso natural das coisas no sentido de sua melhoria, a despeito de tanta extravagância do governo como dos erros da administração" (Smith, 1999, vol I: 600). Mesmo reconhecendo que a legislação possa retardar o curso do desenvolvimento econômico, Smith critica Quesnay por acreditar que o de- 
senvolvimento do corpo político só possa ocorrer sob o "regime da liberdade total e da justiça total". Ao contrário do fisiocrata, ele vê naquela aspiração que move os indivíduos a melhorarem sua situação um princípio que, estando presente em qualquer tempo e lugar, é

"capaz de evitar e de corrigir, em muitos aspectos, os efeitos nefastos de uma economia política, até certo ponto parcial e opressiva. Esta economia política, embora venha indubitavelmente retardar mais ou menos o progresso natural de uma nação para a riqueza e prosperidade, nem sempre é capaz de o entravar e muito menos de o fazer recuar" (Smith, 1999, vol. II, 265).

A explicação para essa diferença só pode residir, mais uma vez, na diversidade das situações encontradas pelos dois pensadores (Rubin, 1979: 167-8). A França do século XVIII era uma sociedade essencialmente rural, com um mercado interno restrito e fragmentado. O desenvolvimento capitalista estava longe de ser uma realidade: era sobretudo um projeto político cuja implementação só poderia ser levada a cabo por uma revolução social. Se a fisiocracia precisa depositar suas esperanças na ação esclarecida do Estado para assegurar a modernização da economia, Smith pode confiar no impulso aquisitivo dos indivíduos para promover o crescimento da riqueza nacional. A despeito das restrições mercantilistas e do poder político da oligarquia que ainda imperavam na Inglaterra do século XVIII, o país tinha uma população urbana crescente, um mercado interno integrado e competitivo e a base da economia - a agricultura - funcionando segundo princípios capitalistas. O franco desenvolvimento do capitalismo agrário e o amadurecimento do processo que levaria à constituição do capitalismo industrial na Inglaterra davam a Smith motivos suficientes para confiar na capacidade das forças econômicas de superar obstáculos políticos e legais.

Importa ressaltar o contraste entre as expressões ideológicas da burguesia na França e na Inglaterra. A primeira levantará a bandeira da universalidade dos direitos - a cidadania e a igualdade civil - contra os particularismos, os privilégios aristocráticos. No entanto, a atitude da burguesia francesa diante do Estado absolutista será muito mais ambígua: que se pense na adesão dos fisiocratas ao "despotismo legal". Mesmo no período pós-revolucionário, o aprofundamento de um programa centralizador e a preocupação com o planejamento racional e com a padronização são prolongamentos de tendências presentes desde Colbert: "afinal, até a padronização da língua francesa faz parte do projeto centralizador do Estado absolutista, um projeto de racionalização que teve sua expressão cultural clássica nos jardins formais de Versalhes" (Wood, 2001: 117). Por outro lado, na Inglaterra,

“[prevaleceu] não o racionalismo cartesiano e o planejamento racional, mas a 'mão invisível' da economia política clássica e a filosofia do empirismo britânico. Não os jardins formais de Versalhes, mas os 
jardins de paisagismo 'natural', aparentemente não planejado.(...) Certamente houve, na Inglaterra, um interesse pela ciência e tecnologia, compartilhado com seus vizinhos europeus.(...) Mas a ideologia característica que distinguiu a Inglaterra das outras culturas européias foi, acima de tudo, a ideologia do 'melhoramento': não a idéia iluminista do aperfeiçoamento da humanidade, mas o melhoramento da propriedade, a ética — e, a rigor, a ciência — do lucro...” (Wood, 2001: 119).

Essa visão de mundo que domina a trajetória da economia política inglesa atingirá seu ponto culminante com o utilitarismo de Bentham. Enquanto Smith afirmava a existência de uma harmonia entre a busca do interesse individual e a realização do interesse geral ao mesmo tempo em que mantinha uma clara distinção entre estes dois termos, Bentham subordina — ou ainda, dissolve - a sociedade aos interesses pessoais. Seu princípio de utilidade consiste em aprovar ou reprovar uma ação

"segundo a tendência a que tem a aumentar ou diminuir a felicidade da pessoa cujo interesse está em jogo (...) A comunidade constitui um corpo fictício, composto de pessoas individuais que se consideram como constituindo os seus membros. Qual é, neste caso, o interesse da comunidade? A soma dos interesses dos diversos membros que integram a referida comunidade." (Bentham, 1979: 4).

Tal será o único sentido admissível para o termo "interesse da comunidade": o único que conta são os interesses individuais e, na medida em que a sociedade não tem qualquer realidade para além dos indivíduos que a compõem, o bem-estar da comunidade consiste apenas no somatório das utilidades individuais. Como cada pessoa sabe o que é útil para si, a melhor maneira de promover o bem-estar social é assegurar o máximo de liberdade para os indivíduos.

Discuta-se agora um outro momento importante da história do pensamento econômico - a revolução marginalista. Entre os países que participarão dessa "revolução" estão, nuclearmente, a Inglaterra, a França e a Áustria. De seu desdobramento e consolidação sob a forma da ortodoxia neoclássica, também tomarão parte, e com destaque, os Estados Unidos e a Suécia.

Talvez cause estranheza, para quem só conhece o livro de 1874, que Walras seja visto aqui como representante da velha tradição do pensamento econômico francês. Isso é patente se se lembrar de sua preocupação com os aspectos e consequiências sociais das relações econômicas. É isso que o levará a elaborar uma obra que é, ao lado de suas pretensões a ser um símile das construções da física, uma tentativa de resposta, do ponto de vista liberal-burguês, ao desafio socialista de então. Veja-se o que dizem Screpanti e Zamagni:

"Walras put forward numerous articulate recommendations for economic policy. His favorite subjects were the nationalization of natural 
monopolies, the stabilization of prices by monetary authorities, the capital market, whose efficiency and reliability should be ensured by the State, and the acquisition of land by the State and its concession in use to private agents in order to increase government revenues. It is worth noting the curious fact that Walras considered himself a 'scientific socialist'.” (Screpanti e Zamagni, 1993: 170).

A obra de Walras reproduz assim, de forma enfaticamente exemplar, o que Marx já havia surpreendido antes como característica marcante do pensamento econômico francês - sua incapacidade de aceitar, sem mais, as consequiências da acumulação de capital. Walras, o que quis dar à economia a mesma metodologia e procedimentos analíticos da mecânica clássica, foi também o adversário de Proudhon, o reformador social, defensor do imposto único, herança fisiocrática que deveria recair sobre os proprietários de terra; o defensor da nacionalização da terra; o incentivador da criação dos bancos populares...

Mais intrigante, contudo, é perguntar-se sobre a trajetória, singularíssima, do pensamento econômico alemão, que rejeitará tanto o paradigma clássico, quanto o neoclássico. País de forte tradição filosófica, de excelência em muitos campos do pensamento, a Alemanha trilhará caminho único no referente ao pensamento econômico baseado na rejeição dos paradigmas dominantes. Tal atitude não impediu que, mesmo recusando o pensamento hegemônico, a Alemanha se colocasse em posição de destaque no contexto mundial como potência de primeira linha.

Esse fato é uma prova expressiva de duas questões importantes: 1) que o desenvolvimento econômico de um país não tem correlação direta com o grau de aderência deste país ao pensamento econômico dominante; 2) que o pensamento econômico de um país é sempre marcado por sua história político-cultural.

Trata-se no essencial de buscar entender: 1) por que o individualismo, o liberalismo, o utilitarismo são, e só poderiam ser, criações inglesas; 2) por que esses paradigmas não terão qualquer repercussão maior na Alemanha; 3) por que esses mesmos paradigmas terão de ser mitigados para serem aceitos na França; 4) e porque eles serão exacerbados na tradição austríaca.

Vários autores buscaram entender a singularíssima trajetória do pensamento econômico alemão, sua recusa em aceitar qualquer teoria abstrata do valor, em que pese a contribuição pioneira e sem maior repercussão na Alemanha de Gossen, em 1854, quando criou a teoria da utilidade marginal.

Tal postura não deve ser vista como extravagância ou idiossincrasia, porque, de fato, é expressão de uma estratégia de superação do atraso alemão mediante a afirmação de sua identidade cultural. É o que se vê quando o pensamento alemão do século XVIII buscou colocar-se no mesmo plano de grande cultura européia de então, dominada pelos herdeiros da cultura latina, pela invocação de sua matriz, que é a cultura helênica. Desse modo, resgatando a cultura helênica, matriz da cultura latina, os alemães não só se colocaram numa posição de destaque no debate cultural de então como mesmo superaram a hegemonia francesa. 
Foi essa a atitude de Goethe, de Schiller e, antes deles, de Winckelman, de Lessing que, no mesmo diapasão de Herder e Fichte, vão constituir um universo de referências fundadas na grande cultura clássica grega que alimentariam a constituição e afirmação da cultura alemã sem qualquer complexo de inferioridade em relação à cultura de origem latina (Rocha, 1999).

Trata-se de uma estratégia surpreendente em seu movimento que, realizando um recuo, capacita-se a avançar, a atualizar-se, a colocar-se como sujeito de plena envergadura no debate intelectual. É esse o papel do romantismo alemão, mesmo em seus destemperos anti-iluministas; foi essa coragem em desafiar o estabelecido que permitiu à cultura alemã sua definitiva emancipação e as fortes marcas que deixará na cultura contemporânea em diversos campos e sentidos: é alemã a primeira universidade efetivamente moderna, que combina ensino e pesquisa, a Universidade de Berlim, criada em 1810, por Wilhelm Humboldt, que também será o criador da moderna lingüística; e são vários os campos em que vai se expressar a excelência do pensamento alemão - na geografia e na história, na filosofia e na física, na química e na matemática, nas ciências do espírito e nas ciências naturais...

Vários autores destacaram a pequena participação dos economistas alemães na construção das grandes tendências do pensamento econômico - tanto no relativo à economia clássica, quanto no referente ao pensamento neoclássico. Essa atitude, coletiva e consistentemente praticada por muito tempo, não deve ser entendida como particular incapacidade intelectual de assimilar princípios teóricos.

O que é decisivo entender aqui é que a Alemanha não participou da constituição e desenvolvimento da teoria econômica dominante por omissão ou incapacidade, mas, decisivamente, por uma opção. Trata-se de uma recusa, de uma rejeição cujas razões revelam muito do desenvolvimento histórico alemão no século XIX.

Lembre-se, desde logo, que os alemães vão desenvolver aspectos particulares do pensamento econômico: é decisiva a contribuição alemã à economia regional com as obras seminais de von Thünen, Alfred Weber, Lösch, Christaller; é também marcante o uso que Friedrich List fez do conceito de proteção à indústria nascente; de John Stuart Mill, para criar o que pode ser visto como o embrião de uma teoria econômica do desenvolvimento.

Essas características do pensamento econômico alemão são, como pode constatar quem se lembre da tradição cameralística de seu mercantilismo, atualizações de uma determinada maneira de ver a vida econômica marcada pelo particularismo da fragmentação político-administrativa, pela presença de regulamentações corporativas etc. O grande sociólogo funcionalista Talcott Parsons surpreendeu o essencial do processo assim:

"El hecho de que una economia industrial se desarrollara en Alemania, en una sociedad ya sumamente estructurada en torno del Estado prusiano y en el contexto de las penetrantes pautas de configuración del conservadorismo prusiano, coloreó sin duda el desarrollo total en mu- 
chos aspectos diferentes. En primer lugar, el 'individualismo económico' no predominó nunca tanto como en los países anglosajones. La mayor participación del gobierno en los asuntos de la economia se tenia por natural y no era resistida, ya se tratara de una questión de propriedad y manejo de los ferrocarriles por el gobierno o del hecho de que fuera Alemania la que introdujó por primera vez un sistema de seguro social de amplio alcance. Es sin duda significativo que la 'economia clásica' nunca arraigara realmente en las universidades alemanes; puesto que no habiendo sido nunca tan sólo una disciplina teórica sino además una ideologia, expresaba un ideal de independencia de la 'empresa' respecto del Estado y otros intereses 'sociales', todo lo cual resulteba afín con la mentalidad alemana” (Parsons, 1967: 97).

A recusa alemã em aceitar a economia clássica ou neoclássica é, na verdade, uma estratégia de afirmação de um outro paradigma que, opondo-se à impessoalidade, à abstração e ao individualismo típicos daquelas teorias, buscará mostrar a organicidade das relações entre o homem e a natureza, denunciando a inautencidade do mundo da racionalidade instrumental, mediante a escolha da cultura em contraposição à civilização; da comunidade em relação a sociedade; da nação, do local, do regional em relação à abstração das relações impessoais. É esse o sentido daquela rica trama filosófico-cultural de que fazem parte os românticos alemães Novalis, Herder, Goethe e seus herdeiros - Schopenhauer, Nietzsche, Tönnies, Spengler...

No referente ao pensamento econômico, a Alemanha vai se notabilizar pela criação de uma corrente - a Escola Histórica Alemã — que tem como característica a denúncia de toda a tentativa de se constituir uma teoria econômica com base em uma teoria abstrata do valor. Essa denúncia apoiava-se na idéia de que qualquer tentativa de ver regularidades, estabilidade nas relações econômicas é tão somente ilusão e charlatanismo, já que o mais permanente da vida econômica é a flutuação, a mudança, a ausência de qualquer ordem. Daí que resulta absurda a tese da existência de uma referência-valor que determinaria os preços. Para a Escola Histórica não é possível fazer-se teoria econômica porque isso implicaria em previsão e esta é impossível em economia. Assim, a reflexão legítima, a única efetivamente racional, seria a histórica, do que decorreria que a Escola Histórica abrisse mão de constituir uma teoria econômica para, afinal, inventar a história econômica (Iglésias, 1959).

Importa frisar a presença - tanto na obra dos autores ligados à Escola Histórica, quanto na de representantes de outras vertentes do pensamento econômico germânico - de uma forte associação entre a vida econômica e a vida da $\mathrm{Na}$ ção, vínculo que se expressa com toda clareza no termo alemão cunhado para designar a economia política: Nationalökonomie. Essas relações de mútua dependência entre a economia e o Estado surgem também nos trabalhos dos autores alemães do final do século XIX e começo do XX, os mesmos que forjaram, bem antes da revolução keynesiana, a base conceitual do planejamento econômico adotado no "capitalismo organizado", bem como no socialismo: 
"The basic problem from this perspective was not the allocation of scarce resources; it was the wider question of the conditions under which the economic order and general welfare were secured. Economics, therefore, was not expected to provide a rationalistic account of optimization in the best of all possible worlds, but to address the question of the possibilities of economic life under various social and political régimes." (Tribe, 1988: 6).

Um contraponto interessante e significativo é a comparação entre o pensamento econômico alemão e o austríaco. Se é de recusa e denúncia a atitude alemã em relação aos paradigmas clássico-neoclássico em economia, será de contribuição de primeira ordem a atitude austríaca. Menger, Weber, Böhm-Bawerk, von Mises, Hayek estão entre os maiores nomes do pensamento neoclássico.

Um capítulo exemplar do que se está dizendo aqui é o chamado "debate sobre o método" que, nos anos 1880, confrontou Menger e Schmoller, o líder da Escola Histórica então.

O centro do debate era o referente à possibilidade de se constituir uma ciência econômica baseada em leis gerais abstratas. Para Schmoller, tanto clássicos, quanto neoclássicos padeciam da mesma fragilidade que era o abstracionismo de suas proposições. Contra isso, ele mobilizou a tese de que a economia só é compreensível quando tomada como conjunto de realidades singulares, histórica e espacialmente determinadas, que estão, o tempo todo, em movimento, o que impediria qualquer generalização. Nas palavras de Screpanti e Zamagni, "Schmoller tried to show how political economy had to be liberated from 'false abstractions' and anchored to solid empirical foundations" (1993: 171).

De qualquer modo, este aparentemente regressista ponto de vista alemão não os impediu de se tornarem a grande potência continental européia já no início do século XX. De outro lado, a formidável contribuição austríaca ao pensamento econômico neoclássico não impediu que a Áustria definhasse como potência ao mesmo tempo de seu sucesso na constituição da ortodoxia neoclássica.

Viena, cidade de Freud e berço da psicanálise, é também berço da versão mais subjetivista da revolução marginalista. É também em Viena que vai se desenvolver uma literatura fortemente marcada pela introspecção, como se vê em Hermann Broch - sobretudo com A Morte de Virgílio -, Robert Musil, Arthur Schnitzler, de tal modo que não será exagero pensar-se em determinantes mais gerais, histórico-materiais, imprimindo certa tendência ao apego à subjetividade que tem aquela cultura. É possível mesmo ir além na identificação desses traços da psicologia social austríaca, lembrando outra característica de sua vida intelectual que é a força com que lá se desenvolveu o neopositivismo, base da filosofia analítica; base, na verdade, do abandono de toda a reflexão sobre o ser, sobre a realidade mesma, para concentrar-se, como único esforço legítimo do pensamento na reflexão sobre a linguagem, sobre a correção dos enunciados.

Transformada em gramática última, essa filosofia austríaca expressa duas questões fundamentais: 1) a inapetência do pensamento contemporâneo pelo ser, 
fenômeno tematizado por Heidegger e que teria uma outra versão, marxista, com Luckács e sua denúncia da crise repesentada pelo abandono da ontologia; 2) essa vocação especificamente austríaca pelo subjetivismo, pela introspecção, pelo abstracionismo, pela linguagem e pela análise como reflexos, em algum sentido, da própria história austríaca, a longa (desde 1648) e melancólica trajetória de impotência do outrora poderoso império "onde o sol nunca se punha".

Principal derrotada na Guerra dos Trinta Anos (1618-1648), potência constrangida pela ascensão da Holanda, da Inglaterra e mesmo da Suécia, da afirmação francesa nos séculos XVII e XVIII, a Áustria, mesmo com as manobras de Metternich em 1815, não voltará ao glorioso de seu passado imperial cada vez mais assemelhado à uma paisagem — Potemkin.

Essa impotência diante de um mundo que tendeu a fugir-lhe ao controle teria produzido, no que se está defendendo aqui, uma ação reativa que foi uma radicalização do ensimesmamento, a busca dos fundamentos da psique humana, a busca dos fundamentos da linguagem, a busca dos fundamentos da ação humana, entendida como escolha entre objetos dados. Foi assim que Bukharin, aluno de Böhm-Bawerk, surpreendeu o essencial da teoria marginalista em sua versão austríaca. Em lugar da produção, o consumo; em lugar do investimento, a escolha; em lugar da lógica da acumulação, a lógica da fruição. Trata-se de buscar maximizar a satisfação do consumidor: a hegemonia da lógica do rentista.

Inaugurada por Menger, em 1871, essa tradição teórica desdobrar-se-á, mantendo, no essencial, a mesma radical adesão ao subjetivismo e ao liberalismo de Menger a von Mises, de Böhm-Bawerk a Hayek. Discutindo o "fracasso" do liberalismo vienense, Janik e Toulmin comentam que

"no fue estéril el liberalismo vienés. Sus teóricos aún ocupan puestos elevados en la historia de las ciencias economicas; por ejemplo, la teoria de las utilidades marginales de Menger - tan característicamente vienesa en el acento que puso sobre los fatores psicológicos y subjetivos que fundamentan el valor - es aún principio central para muchos economistas modernos" (1973: 64). ${ }^{2}$

\footnotetext{
${ }^{2}$ Neste sentido o "fracasso" do liberalismo vienense parece ter desobrigado os pensadores austríacos de preocupações "pragmáticas" ou "concretas", permitindo uma dedicação maior às questões abstratas (ênfase na "teoria pura") e aos debates teóricos (ver os verbetes sobre "debates clássicos" em Boettke, 1994: 459-485). Por outro lado, as limitações do liberalismo na Áustria também estiveram na base da formulação do austromarxismo por Viktor Adler, cujo "socialismo transcendía las limitaciones del liberalismo mediante la ampliación de sus objetivos, estaba en continuidad con los ideales de razón y progreso que los liberales habian suscrito" (Janik e Toulmin, 1973: 64). O acento subjetivo do pensamento de Adler, a influência neokantiana sobre sua obra, sua ênfase teórica no papel da consciência, no caráter "mental" dos fenômenos econômicos, sugerem a oportunidade de discutir outra especificidade austríaca: o seu marxismo. O que há de específico na elaboração de autores como Adler, Bauer e Hilferding quando comparados aos marxistas alemães ou ingleses, por exemplo? Tema que, sem dúvida, é interessante, mas vai além do escopo deste trabalho.
} 
Isolada entre uma Alemanha que se unificará e se expandirá imperialisticamente e os velhos adversários na geopolítica européia - França e Inglaterra - , a Áustria buscou afirmar sua identidade e grandeza pela originalidade aristocrática de sua corte, que continuou a seguir a pompa da Espanha Habsburgo; pelo refinamento de sua arquitetura que se recusou a abandonar o barroco-rococó; pela sofisticação intensa e irônica de sua literatura, de que é exemplar a iconoclastia de Karl Krauss. É esse mundo de melancolia e refinamento, de desespero e orgulho aristocrático que se vê no ornamentalismo de Klimt, no paroxismo de Münch, no extremado do romantismo de Mahler, na revolução formal de Schöenberg.

Civilização crepuscular, outonal, diria Huizinga, a Áustria fin-de-siécle de outro siécle foi também capaz de abrir-se para o novo. Isso é particularmente importante, visível no campo do pensamento econômico. Se são genuinamente austríacos Menger e Hayek, o são também Schumpeter e Hilferding. É que a Áustria pôde ousar, sua posição periférica no contexto do grande capital permitiu-lhe certa liberdade de pensamento, certo distanciamento do consagrado nas grandes potências.

É o que se vê em Menger. A análise de sua obra principal, de 1871, permite identificar diversos desdobramentos. O livro está organizado em oito capítulos cuja leitura permite captar uma linha de desenvolvimento que pode levar a caminhos distantes do mainstream da teoria econômica. ${ }^{3}$

A elaboração inicia-se pela "doutrina geral dos bens". Menger diferencia os bens de primeira ordem ("bens necessários para o atendimento direto e imediato das [nossas necessidades]") os bens de "ordem superior", que têm "nexo causal apenas indireto para a satisfação de tais necessidades" (1983: 246). Essa concepção possibilita a introdução de elementos dinâmicos. Em primeiro lugar, o tempo e a incerteza. "O processo por meio do qual os bens de ordem superior são transformados em bens de ordem inferior (...) obedece ele também às leis da causalidade"; e "o conceito de causalidade é inseparável do conceito de tempo" (1983: 253). O fator tempo não é eliminado na transformação dos bens de ordem superior em bens de ordem inferior. Daí, há o espaço para a incerteza:

"portanto, os bens de ordem superior adquirem e fazem valer a sua qualidade de bem não em relação a necessidades imediatamente presentes, mas apenas em relação a necessidades que, de acordo com a previsão humana, só existirão concretamente no momento em que se encerrar o processo de produção de que vimos falando" (1983: 254).

\footnotetext{
${ }^{3}$ A presença da mesma ascendência teórica em autores tão distintos como Schumpeter e Hayek torna-se compreensível pela leitura de Menger. Hayek (1984: 203) explicita as diferenças entre os austríacos e a visão legada por Walras e sugere que se Menger tivesse continuado sua elaboração "...it would have become even more apparent than in his introductory part (which is the Grundsätze) that what he was aiming at was rather to provide tools for what we now call process analysis than for a theory of static equilibrium".
} 
Certeza quanto à quantidade e qualidade dos bens só pode ter quem dispõe "direta e imediatamente" de bens de ordem inferior. Quanto aos de ordem superior, "determinada margem de incerteza e insegurança quanto à quantidade e à qualidade do produto final (...) é comum a todos os setores da produção" (p. 255). E acrescenta:

"quanto mais numerosos forem os elementos que intervêm no processo causal da produção dos bens - elementos esses que desconhecemos, ou se os conhecemos, escapam ao nosso controle - tanto maior será a nossa incerteza quanto à qualidade e à quantidade do produto final do processo causal inteiro, isto é, dos bens correspondentes de ordem inferior (...) essa incerteza representa um dos elementos essenciais da incerteza econômica dos homens" (p. 256).

Em seguida, Menger comenta as causas do aumento do bem-estar humano e critica Smith por ter deixado de lado outros fatores relevantes, além da divisão do trabalho. No essencial, trata-se "do efeito multiplicador que a utilização de bens de ordem superior tem sobre os bens de consumo (bens de primeira ordem) para o atendimento das necessidades humanas" (p. 257). E para o desenvolvimento desses bens de ordem superior, o limite é o conhecimento disponível. Segundo Menger:

" $[\mathrm{O}]$ s bens de consumo, que antes eram simplesmente o resultado de uma coincidência casual das condições de seu surgimento, passam a ser, no momento em que os homens assumiram o controle do processo, um produto da vontade humana (dentro dos limites impostos pela Natureza), e as quantidades de bens disponíveis só encontrarão um limite: a compreensão do nexo causal entre as coisas e fatores, mais o domínio e controle desse processo por parte dos homens. O conhecimento progressivo do nexo causal das coisas com o bem-estar humano e o domínio progressivo das condições mais remotas dos mesmos conseguiram, portanto, levar a humanidade do estágio primitivo e de miséria extrema para o estágio atual de cultura e bem-estar (...) e (..) também no futuro, é dessa forma que se dará o progresso econômico da humanidade" (1983: 257).

Na medida em que "os homens avançam na evolução cultural”, “existe um alto grau de divisão de trabalho", e " (...) pessoas isoladas produzem individualmente grandes quantidades de bens de ordem superior, fiando-se na suposição (via de regra, correta) de que outras pessoas produzirão as correspondentes quantidades de bens complementares" (p. 264). Desencontros entre essas quantidades de bens complementares determinam o surgimento de distúrbios na Economia: "distúrbios que na linguagem do dia-a-dia costumam chamar-se de anormalidades, mas que na realidade são perfeitamente normais, por decorrerem de uma lei inflexível da Economia" (p. 265). 
O caráter subjetivo do valor é afirmado claramente no capítulo III:

“...o valor não é algo inerente aos próprios bens, não é uma propriedade dos mesmos e muito menos uma coisa independente, subsistente por si mesma. O valor é um juízo que as pessoas envolvidas em atividades econômicas fazem sobre a importância dos bens de que dispõem para a conservação de sua vida e de seu bem-estar; portanto só existe na consciência das pessoas em questão (...) o valor é por sua própria natureza algo totalmente subjetivo" (p. 287).

Essa visão permite romper a relação entre trabalho e valor, mas, ao mesmo tempo, permite enfatizar o papel do conhecimento, em um sentido muito específico: para Menger, "podemos observar oscilações de valor que encontram sua razão última simplesmente no fato de se modificar o conbecimento da importância de que os respectivos bens se revestem para nossa vida e nosso bem-estar" (grifos do autor) (983: 306). Nesse capítulo a atividade empresarial (envolvendo informação, cálculo de viabilidade econômica, ato de vontade e supervisão) é discutida, articulando a especialização do trabalho e o aumento do porte das empresas e a ampliação do tempo da atividade empresarial. Menger comenta a concentração do papel do empresário em sociedades anônimas (tarefas de canalização de sua riqueza, seleção de colaboradores e controle do empreendimento).

Finalmente, debatendo a origem do dinheiro, Menger atribui a existência dessa instituição não a uma "invenção" do Estado, mas à ação dos indivíduos, cujo "exercício e (...) hábito certamente contribuíram muito para transformar as respectivas mercadorias de maior vendabilidade em mercadorias que, aos poucos, passaram a ser aceitas em troca de outras não por muitos, mas por todos os indivíduos" (p. 376). O Estado sanciona um bem que é dinheiro, oficializando sua capacidade de "representação universal" (p. 378). Nesse sentido, a abordagem de Menger é uma aplicação do individualismo metodológico à compreensão das instituições que seria trabalhada posteriormente por Hayek. Sua teoria tem, portanto, elementos dinâmicos importantes, donde o espaço para desenvolvimentos posteriores, na linha de Schumpeter e outros, define caminhos que desviamse do pensamento mainstream. Três seriam as vias desse afastamento: o papel dos bens superiores no progresso econômico, a identificação do empresário na vida econômica e a consciência da existência da incerteza — derivada do tratamento dado ao tempo na vida econômica.

Finalmente, lembre-se a convergência, em algum nível, da tese de Hayek sobre a produção da ordem a partir de uma certa desorganização originária, com os aportes da teoria da autopoiesis, de Maturana e Varela (2001), como sinal de um pensamento que tem forte incidência no debate contemporâneo, para além de qualquer reducionismo formal e obliterante. De qualquer modo, essa tradição é importante para o pensamento econômico na medida em que convoca-o para campos mais amplos e densos que os rarefeitos espaços em que o mainstream teima em aprisioná-lo. 
As abordagens convencionais da história do pensamento econômico são dominadas pela idéia de um progresso contínuo em direção ao estado atual da teoria. Este último é o parâmetro a partir do qual as obras do passado são compreendidas e avaliadas. A história da ciência é vista como um processo movido por desenvolvimentos internos às teorias, em que a eliminação do "erro" conduz inexoravelmente ao estado atual do conhecimento. É fácil ver que, a partir dessa perspectiva, a existência de estilos nacionais de economia política deve ser impugnada ou tratada como um sinal da permanência de resquícios metafísicos, "erros" ou "incoerências" a serem eliminados com o desenvolvimento da teoria.

À primeira vista, os desenvolvimentos no ensino e pesquisa em economia ao longo das últimas décadas poderiam sugerir que este fosse o caso. Escrevendo ainda no início dos anos 70, Harry Johnson notava que as investigações sobre o equilíbrio geral e o emprego de métodos matemáticos e econométricos haviam provocado uma "revolução" na pesquisa econômica. Essa revolução teria ocorrido sobretudo nos Estados Unidos, substituindo o estilo "filosofante" da velha economia política pela pesquisa apoiada nas novas técnicas matemáticas. Johnson explicava esta vantagem apelando para características institucionais do sistema universitário americano que o tornariam supostamente superior ao dos países europeus e concluía: "economics has, in fact, become an English-language discipline" (Johnson, 1973: 74). Como resultado, a comunidade acadêmica dos economistas estaria dividida em três grupos bastante diversos: 1) os que, tendo passado por um programa de pós-graduação de excelência (top-notch) nos EUA, aprenderam e se apaixonaram pelas novas técnicas de pesquisa, aplicando-as em seus trabalhos; 2) os que, mesmo tendo passado por bons programas de pós-graduação para obter uma posição na Universidade, depois disso se acomodaram e não se envolveram no desenvolvimento de pesquisas; e 3) os que nunca passaram por um programa de pós-graduação de excelência. Segundo Johnson:

"The first group constitutes the elite of the profession (...). Their style is an international style, though primarily American in origin and outlook, and frequently they have to maintain it in the face of hostility and resentment from their departmental colleagues and of inadequate institutional support. (...) It is the other two groups that constitute the repository of differences in national styles." (Johnson, 1973: 67).

Escapa aos objetivos deste ensaio discutir em que medida os desenvolvimentos nas duas últimas décadas deram sustentação a essa tese - de que as diferenças nacionais de estilo tenham ficado relegadas ao "baixo clero" acadêmico, sendo substituídas por um "estilo internacional" (ou americano). ${ }^{4}$

\footnotetext{
${ }^{4}$ É algo que certamente seria interessante investigar em outro artigo. Baumol (1995: 192), por exemplo, é um dos que apontam a permanência de diferenças significativas entre os estilos americano e europeu de fazer teoria econômica.
} 
O que é importante destacar a título de conclusão é que a compreensão dessas diferenças de estilo ou identidade requer uma outra maneira de abordar a história do pensamento econômico, distinta da convencional. Ao invés de partir da premissa de que o desenvolvimento da ciência pode ser representado como um processo único e linear de acúmulo de conhecimentos, trata-se de investigar a maneira como a ciência é efetivamente produzida, isto é, por comunidades de pesquisadores que, apesar de ligadas entre si, têm formas e regras de organização distintas e que, mesmo partilhando problemas e conhecimentos, partem de tradições intelectuais e contextos sociais diferenciados.

Nesse caso, a tarefa de reconstituir a história do pensamento econômico envolve um duplo desafio. Trata-se de compreender de que maneira as especificidades histórico-culturais de cada sociedade moldaram estilos particulares de economia política e, ao mesmo tempo, deram origem a teorias razoavelmente coerentes e cuja pretensão de validade extrapola os contextos específicos em que foram criados.

Ao invés de um conjunto único de conceitos e métodos universais, a teoria econômica que emergirá dessa reconstituição se apresentará como um discurso sujeito a influências culturais, logo, heterogêneo e plural. Tal imagem representa certamente um desafio para as concepções metodológicas que vêm orientando o desenvolvimento da disciplina, concepções que ainda se apóiam largamente numa visão positivista do método da pesquisa científica " which, in many ways, have impoverished our conceptions of basic economic processes and limited the capacity of economic doctrine to provide the basis for an 'economic imagination'" (Tribe, 1988: 4).

\section{REFERÊNCIAS BIBLIOGRÁFICAS}

BAUMOL, W. (1995). What's different about European economics? Kyklos, 48 (2).

BENTHAM, J. (1979). Uma introdução aos princípios da moral e da legislação. (Os pensadores). São Paulo, Abril Cultural.

BOETTKE, P. , org. (1994). The Elgar companion to Austrian economics. Aldershot: Edward Elgar.

BUJARIN, N. (1974). La economia política del rentista (crítica de la economía marginalista). Buenos Aires: Ediciones Pasado y Presente

HAYEK, F. (1984). “The place of Menger's Grundsätze in the history of economic thought”. In: NISHIYAMA, C.; LEUBE, K. The essence of Hayek. Stanford: Hoover Institution/Stanford University.

IGLÉSIAS, F. (1959). Introdução à historiografia econômica. Belo Horizonte: FCE/UFMG.

JANIK, A.; TOULMIN, S. (1973). La Viena de Wittgestein. Madri: Taurus.

JOHNSON, H. (1973). National styles in economic research: the United States, the United Kingdom, Canada, and various European countries. Daedalus, $\mathrm{n}^{\circ} 102$.

MARX, K. (1974). Para a crítica da economia política. (Os Pensadores). São Paulo: Abril.

MARX, K. (1982). O capital: crítica da economia politica. Vol. I, São Paulo: Difel.

MATURANA, H.; VARELA, F. (2001). A árvore do conbecimento. São Paulo: Palas Athena.

MENGER, C. (1983). Princípios de economia política. São Paulo: Abril Cultural.

MERTON, R. (1965). Teoria y estructura sociales. México: F.C.E.

PARSONS, T. (1967). Ensaios de teoria sociológica. Buenos Aires: Paidós. 
QUESNAY, F. (1991a.). "Le droit naturel”. In: Physiocratie: droit naturel, tableau económique et autres textes. Paris: Flammarion.

QUESNAY, F. (1991b). “Maximes générales du gouvernement économique d'un royaume agricole”. In: Physiocratie: droit naturel, tableau económique et autres textes. Paris: Flammarion.

ROCHA, J. C. (1999). Introdução a máscaras e mímesis: a obra de Luiz Costa Lima. Rio de Janeiro: Record.

ROUSSEAU, J. J. (1958). Obras. $1^{\circ}$ vol.. Porto Alegre: Editora Globo.

RUBIN, I. I. (1979). A history of economic thought. London: Ink Links.

SCREPANTI, E.; ZAMAGNI, S. (1993). An outline of the history of economic thought. New York: Clarendon Press.

SMITH, A. (1999). Inquérito sobre a natureza e as causas da riqueza das nações. Lisboa: Fundação Calouste Gulbenkian.

TRIBE, K. (1988). Governing economy: the reformation of the German economic discourse. Cambridge: Cambridge U.P.

WOOD, E. M. (2001). A origem do capitalismo. Rio de Janeiro: Jorge Zahar. 